\title{
JOURDAIN, RUSSELL AND THE AXIOM OF CHOICE: A NEW DOCUMENT
}

\author{
I. Grattan-Guinness \\ Middlesex U. Business School \\ Hendon, London NW4 4BT, UK \\ Centre for Philosophy of Natural and Social Science, L.S.E. \\ London WC2A $2 \mathrm{AE}$, UK \\ IVOR2@MDX.AC.UK
}

\section{CAREER}

P hilip Edward Bertrand Jourdain (I879-1919) went up to Trinity College Cambridge in 1899 with a scholarship in mathematics. Two years later he attended a special College course in mathematical logic offered by Bertrand Russell, the first of its kind ever taught in a British university. This contact with Russell was of major consequence for his intellectual career, for he focused upon set theory and its history, and also on the histories of mathematical analysis and of logic, and aspects of the history and philosophy of mechanics and of science. ${ }^{\mathrm{I}}$ He corresponded at length with Russell until his death in 19I9; the exchange forms the core of my book on their relationship. ${ }^{2}$

From his youth Jourdain suffered from a creeping paralysis called "Friedreich's ataxia". It prevented him from taking the Part 2 Tripos; thus he did not graduate as a Wrangler and so could not compete for a fellowship at Trinity. So he made his living from a few scholarships and from freelance writing as an

I Jourdain's principal historical writings are gathered together in Selected Essays on the History of Set Theory and Logics (I906-I9I8), ed. I. Grattan-Guinness (Bologna: CLUEB, I99I) and his introduction to G. Cantor, Contributions to the Founding of the Theory of Transfinite Numbers, trans. and ed. Jourdain (La Salle, Ill.: Open Court, I9I5; repr. New York: Dover, 1955).

${ }^{2}$ I. Grattan-Guinness, Dear Russell-Dear Jourdain: a Commentary on Russell's Logic, Based on His Correspondence with Philip Jourdain (London: Duckworth; New York: Columbia U. P., 1977); hereafter " $R J$ ". 
independent scholar. In particular, the American house The Open Court Publishing Company employed him, especially from I9I2 on their principal journal The Monist, commissioning papers (and also some books) from colleagues, in particular Russell. He seems to have served as its general editor soon after the death in February 1919 of its founder editor, Paul Carus, but he died himself early in October. Those last months form the time-frame of this paper.

\section{OBSESSION}

Jourdain's principal research interest in the foundations of mathematics came to focus upon the denumerable "axiom of choice" in set theory and mathematics, as Ernst Zermelo named it a few years after introducing it in $1904 .{ }^{3}$ Take an infinite ensemble of non-empty and pairwise disjoint sets and choose a member from each set in independent actions; then the axiom asserts that the collection of chosen members can always be regarded as a genuine set. But this manner of forming a set roused considerable doubts and opposition among many (though not all) set-theorists and logicians. Some of them rejected the axiom altogether; others tried to reprove theorems that used the axiom by proofs that avoided it; several sought hopefully more congenial assumptions that were logically equivalent to the axiom, and eventually many came to light. ${ }^{4}$ Logicists such as Russell faced the additional difficulty of expressing the infinitude of independent choices within his finitary predicate calculus; he had spotted the need for the axiom shortly before Zermelo, and called it the "multiplicative axiom" after the mathematical context involved (namely, defining infinite products of numbers). ${ }^{5}$

As the years passed the community accepted, with various degrees of shoulder-shrugging, the unavoidability of the axiom in quite a wide range of settheoretic and mathematical contexts. But Jourdain always believed that it was provable from the other axioms, and published a variety of "proofs", all of which failed either by requiring assumptions that did not hold in sufficient generality, or by drawing upon deductions that assumed some form of the axiom. By the late I9IOs, sensing his forthcoming demise, he produced a proof that he pub-

${ }^{3}$ E. Zermelo, "Beweis, dass jede Menge wohlgeordnet werden kann”, Mathematische Annalen 59 (1904): 514-I6.

${ }^{4}$ See especially H. Rubin and J. E Rubin, Equivalents of the Axiom of Choice, and ed. (Amsterdam: North-Holland, 1985).

5 The history of this/these axioms has been charted in much detail. See especially J. Cassinet and M. Guillemot, "L'axiome du choix dans les mathématiques de Cauchy (I82I) à Gödel (I940)", 2 vols. (U. of Toulouse double docteur d'état des sciences, I983); F. A. Medvedeff, Rannyaya istoriya aksiomi vibora (Moscow: Nauka, 1982); and G. H. Moore, Zermelo's Axiom of Choice... (New York: Springer, 1982). RJdiscusses the axioms in the contexts of the correspondence. 
lished very widely in various levels of elaboration in Mind, Nature, Science Progress, and even the French Academy of Sciences, each paper carrying as its title a translation of Zermelo's 1904 title. $^{6}$

In earlier years Jourdain had corresponded with several set-theorists, and had quoted from the letters of its chief founder Georg Cantor in some of his own papers. When Cantor died in 19I8, the Swedish mathematician Gösta MittagLeffler, who had published Cantor in his journal Acta Mathematica in the I88os, planned to write a biography, and knew of Jourdain's contacts with Cantor from his own correspondence with Jourdain. So he asked for the original letters from Jourdain's executors, the philosopher A. E. Heath and the historian and mathematician J. M. Child (who also took major positions on The Monist). On I2 May 1922 Child sent the letters in the manner in which Jourdain had kept them, stuck in two thick notebooks upon the pages of which he had written or sketched many of his replies. As well as the Cantor letters, ${ }^{7}$ the notebooks contained dozens of the Russell letters mentioned earlier, and several others of interest.

Child also included the manuscript of Jourdain's last paper on the proof, which contained quite a lot of historical background including a quotation and some other information from Cantor. Child recalled that "Just a week before he died he spoke confidently to me about the matter, and seemed to think that he had overcome the last logical difficulties of the proof"; so he asked "would you do me the favour of considering it". Mittag-Leffler published it in the Acta, but expressed his reluctance in a note at its head. ${ }^{8}$

\section{DOCUMENT}

In his last days Jourdain begged colleagues to come to his home in Fleet, Hampshire to hear the new proof. He was especially anxious to talk to Russell, who eventually agreed to a visit late in September 19I9; but by then Jourdain was beyond communication, and no visit by Russell occurred before his death on I October. However, a document exists in the Russell Archives that Jourdain had prepared specifically for Russell's attention, and indeed must have come into his hands; it has been drawn to my attention very recently. Apparently it arrived in the Archives in the late 1980 os from the Russell Estate, a legal entity that had been

${ }^{6}$ For Jourdain bibliography see $R J$, pp. 197-8, or Moore (n. 5), pp. 356-7.

7 I. Grattan-Guinness, "The Correspondence between Georg Cantor and Philip Jourdain”, Jahresbericht der Deutschen Mathematiker-Vereinigung 73 (197I): part I, pp. III-3O.

${ }^{8}$ P. E. B. Jourdain, "A Proof That Any Aggregate Can Be Well-Ordered”, Acta Mathematica 43 (1922): 239-6I. Child's letter to Mittag-Leffler, and some related correspondence, is conserved at the Institut Mittag-Leffler, Djursholm, Sweden. The rest of Jourdain's Nachlass is lost. 
set up after Russell's death in 1970 to handle materials that came posthumously to light in his last home in Wales and elsewhere, and to fulfil certain requirements that Russell had stipulated in his will; it was wound up after his widow Edith died in 1978. The history of the document after 1919 is not known, but it is listed without an author in the 1992 catalogue of the second Russell Archives. ${ }^{9}$

While the document is unsigned, Jourdain is clearly the author. While untitled, the document elaborates Jourdain's last proof; it seems to be complete. While undated, its contents surely place it in his final period of life; it may well be one of the papers to which Jourdain referred in letters to Russell in March and April I9I9 but which appeared to have been lost. ${ }^{\mathrm{IO}}$ His intended audience is indicated at the end by a reference to "you (and Whitehead and Hardy)", which echoes some unfortunate sarcasms that end his second piece in Mind. ${ }^{\mathrm{II}} \mathrm{It}$ is not in his hand, which had become very hard to read in his last years; his anonymous amanuensis seems to have been used to writing mathematical symbols.

\section{ARGUMENT}

While the axiom of choice was needed in a wide variety of contexts, Cantor's original motivation held a special attraction. In order to guarantee the generality of set theory, especially basic properties such as comparability, he had announced his "well-ordering principle", that all the members of any set could be laid out in "well order", like the sequence $O$ of positive ordinals I, 2, 3, ..; that is, with a first member, and a unique successor both to each non-final member and to each finite or infinite subset that does not contain the final member. No proof had been found before Zermelo's controversial proposal; Emile Borel, who was sceptical of the axiom, soon pointed out that the principle itself was equivalent to the axiom. ${ }^{\text {I2 }}$

In his last proof of the principle Jourdain attempted to show that all the members of any set $M$ could be arranged in one-one correspondence with some set of ordinals without needing to make any choices. In the version presented in this document he constructed all "chains" (his name) of $M$ of "ordinal type" (Cantor jargon) $n$, that is, well-ordered sequences of the members of $M$ that are isomorphic to the ordinals from I to $n$. Each individual member of $M$ formed a chain $k_{1}$ of type $\mathrm{I}$, each ordered couple of members gave a chain $k_{2}$ of type 2 ,

${ }^{9} \mathrm{~B} \& \mathrm{~S}$, p. 354. The five-leaf document is in RA2 910, box II.69.

Io $R J$, pp. I46, I49.

II P. E. B. Jourdain, “A Proof That Any Aggregate Can Be Well-Ordered”, Mind, n.s. 28 (I9I9): 382-4; compare him in RJ, pp. I49-5I.

${ }^{12}$ F. E. J. E. Borel, "Quelques remarques sur la théorie des functions", Mathematische Annalen 60 (I905): 194-5. 
then $k, \ldots$, up to taking all members of $M$ (when the chain "exhausts" $M$ ). Form the class $K_{n}$ of $k_{n}$ s for any ordinal $n$, and correlate each $k_{n}$ with the chain $k_{(n-1)}$ in $K_{(n-1)}$ that is a well-ordered "segment" of it, and also take the additional member of $k_{n}$; then $k_{n}$ as a "direct continuation" of $k_{(n-1)}$. Repeat the correlation for $k_{(n-1)}$ on $k_{(n-2)}, \ldots$ down to $k_{2}$ on $k_{1}$. For example (mine), if $M$ consists of the eight members $\{a b c d e f g h\}$, then one of its classes of direct continuations is

$$
(c, d, h, e, b ; c, d, h, e ; c, d, b ; c, d ; c),
$$

where commas mark out the members of a chain, and each semicolon separates a chain from one of its direct continuations that is written at its left and a segment at its right. He permitted multiple use of members; in effect he was treating $M$ as a multiset.

Jourdain explained this construction in somewhat pedantic detail when $M$ contained three members: "Each of the classes of d[irect] c[ontinuation]s determines uniquely a chain of $M$ of type 3." This situation obtains also for "any inductive ordinal" $n$ (for example, when $n=526$ ). Similarly, when the chains of "all inductive suffixes" $n$ are laid out, its class of chains of type $n$ "merely adds a chain of type $n$ in a determined way to each class of d[irect] c[ontinuation]s previously formed" by a rule that "is an intension which determines a set of classes of $\mathrm{d}$ [irect] c[ontinuation]s each of which contains chains of all inductive types" less than $n$. Further, these chains can be well-ordered by inclusion, without any need to make choices.

Jourdain then claimed that these properties hold even if $n$ was a limit ordinal such as Cantor's smallest one, $\omega$, that succeeded $O$, so that his method of forming all chains and direct continuations at each stage delivered the order-type $\omega$ choice-free, as desired: "We have to construct many [direct continuations] in order to avoid arbitrary selections; we do not assume the many is all possible ones (so that we do not conclude that there is a prosecuted trespasser from the proposition that all trespassers are prosecuted)...." "I think, then," he concluded,

that it is proved that we can construct theoretically chains that exhaust $M$ without finding a rule to pick out one term from each of a set of (quite general) classes. I did not try to solve the problem in the way you (and Whitehead and Hardy) will think-in spite of my protests-I do, which direct method seems hopeless to me also. But this fruitless method is not the only one.

Maybe by "the direct method" he meant some version imitating Zermelo's own proof of $1904 .{ }^{13}$

${ }^{13}$ Compare RJ, p. I49. 


\section{DIAGNOSIS}

However, Jourdain's confidence was excessive; as before, limit ordinals $L$ are too elusive for this new proof also. Cantor had specified each one as the first transfinite ordinal succeeding the denumerable well-ordered sequence of ordinals launched by the previous one, and lacking an immediate predecessor. So $L$ was not sitting at the end of some sequence of ordinals awaiting the arrival of boarders; in particular, the smallest limit ordinal $\omega$ lay beyond $O$, and no totality of direct continuations would deliver it in the manner that Jourdain hoped. He failed to distinguish his systematically exhaustive construction of chains of each type $n<L$ from the existence of sets that contained chains of every type $n<L$; a proof of the well-ordering principle required them, and could only be obtained by choosing from among the chains available. Each chain is somewhere but none is everywhere. His constructions of chains and direct continuations of $M$ were structurally similar to some of the maximal principles in set theory and some algebras that were found later to follow from the axiom, or be logically equivalent to it-but not avoid it!

In his letter of 1922 to Mittag-Leffler, Child reported that in his last days Jourdain had rehearsed with him an indirect proof by contradiction of the principle that emulated Pierre Fermat's proof method by infinite descent in number theory: assume that some infinite set $S$ cannot be well-ordered and prove that the same fate awaits a set of lesser ordinality than $S$, and so on down to some finite set. But Child had found no text; had one turned up, then some form of question-begging would surely have been found in its course. 